archives-ouvertes

\title{
Heart and anorexia nervosa
}

\author{
Abdallah Fayssoil, Jean Claude Melchior, Mouna Hanachi
}

\section{To cite this version:}

Abdallah Fayssoil, Jean Claude Melchior, Mouna Hanachi. Heart and anorexia nervosa. Heart Failure Reviews, Springer Verlag, 2019, 10.1007/s10741-019-09911-0 . hal-02435138

\section{HAL Id: hal-02435138 \\ https://hal.sorbonne-universite.fr/hal-02435138}

Submitted on 10 Jan 2020

HAL is a multi-disciplinary open access archive for the deposit and dissemination of scientific research documents, whether they are published or not. The documents may come from teaching and research institutions in France or abroad, or from public or private research centers.
L'archive ouverte pluridisciplinaire HAL, est destinée au dépôt et à la diffusion de documents scientifiques de niveau recherche, publiés ou non, émanant des établissements d'enseignement et de recherche français ou étrangers, des laboratoires publics ou privés. 
Heart and anorexia nervosa

\author{
Abdallah Fayssoil ${ }^{1,2,3} \cdot$ Jean Claude Melchior ${ }^{1} \cdot$ Mouna Hanachi $^{1}$
}

Abstract

Anorexia nervosa, one of the more frequent and severe eating disorders, is a chronic psychiatric disease with potentially serious somatic consequences. This behavioral symptomatology leads to weight loss, undernutrition, and more or less severe-

potentially life-threatening — somatic complications including respiratory, hepatic, digestive and cardiac features, electrolyte

disturbances, endocrine and bone impairment, immunodepression, and related opportunistic infections. In this review, the authors report an overview of cardiac diseases in this disease.

Keywords Anorexia nervosa $\cdot$ Heart $\cdot$ QT interval $\cdot$ Echocardiography $\cdot$ Mortality

\section{Introduction}

Anorexia nervosa, one of the more frequent and severe eating disorders, is a chronic psychiatric disease with potentially serious somatic consequences [1]. Its prevalence varies between 0.9 and $3 \%$ in women and between 0.16 and $0.3 \%$ in men [2]. Anorexia nervosa (AN) is characterized by an emotional and cognitive incapacity to maintain a normal weight and by an active fight against the sensation of hunger [3]. This behavioral symptomatology leads to important weight loss, undernutrition, and more or less severe - potentially life-threatening-somatic complications including respiratory, hepatic, digestive and cardiac features, electrolyte disturbances, endocrine and bone impairment, immunodepression, and related opportunistic infections [1]. In this review, we report an overview of cardiac complications reported in patients with $\mathrm{AN}$.

\section{Heart complications in AN}

Among medical complications described during AN, cardiac features are frequent, reaching $80 \%$ in some studies $[4,5]$. These complications range from morphological cardiac abnormalities to electrical abnormalities with a potential risk of sudden death [6-10]. Cardiac abnormalities may involve the myocardium, the pericardium, the mitral valve, and the conduction system. Cardiac histological studies reported vacuolar degeneration, myocardium attenuation, and moderate interstitial fibrosis, without inflammation or necrosis [11]. In clinic, it has been reported left ventricular (LV) dysfunction, cardiac hypotrophy, mitral valve prolapse, pericardial effusion $[4$, 12], and QT long prolongation. In this context, electrocardiogram (ECG) and Doppler echocardiography should be routinely performed in patients with AN.

\title{
Electrocardiogram
}

Electrocardiogram should be systematically performed in all patients with AN especially in purgative forms (laxatives and more rarely diuretic abuses, vomiting...) with a particular focus on QT duration and heart rate. Indeed, ECG abnormalities are frequent in this disease and include bradycardia, increased QT interval, increased QT dispersion, QRS amplitude reduction, T wave, and ST non-specific abnormalities [13-16]. The most common finding is bradycardia, affecting $36 \%$ of patients, in the study by Dec et al. [17] and 95\% in the study by Palla et al. [13], depending of the severity of underweight and malnutrition. Bradycardia may be in relation with 
hypothermia and seems to be a compensatory mechanism in the context of prolonged starvation [18]. Another explication of bradycardia may be an increase of the vagal tone and a decrease of sympathetic tone [7, 18]. Kollai et al. [19] reported a higher cardiac vagal tone in patients with AN with a significant correlation between cardiac vagal tone and percent weight loss ( $r$ 0.69, $p$ 0.017). Significant conduction block are rare. Indeed, rare cases of second-degree atrioventricular block (Mobitz Type I), as well as junctional rhythm escape and sinus node dysfunction, have been reported in the literature [20-22].

Clinicians should mainly focus on QTc interval and QT dispersion in patients with AN. The QT dispersion represents the difference between the maximum and the minimum QTc across a 12-lead ECG and is considered higher when more than $60 \mathrm{~ms}$. An increase of the QT interval and the QT interval dispersion are classically in relation with a regional difference in myocardial excitability recovery, and can expose the patient to arrhythmia $[23,24]$. A low body mass index (BMI) and a rapid weight loss have been reported to be associated with QTc interval prolongation and dispersion [12]. Also, the reduction of LV mass has been reported to be associated with an increase of QT interval and QT dispersion $(r=-0.69, p<0.01)$ [25]. QT interval dispersion is negatively associated with resting metabolic rate [26].

\section{Doppler echocardiography}

The aim of the Doppler echocardiography is to assess cardiac function, hemodynamic status, and to search for the presence of pericardial effusion and mitral regurgitation.

\section{Myocardium}

With starvation that leads to a reduced weight, patients develop usually a reduction of cardiac mass [27]. Echocardiography performed in malnourished AN patients found reduction of LV wall thickness and LV mass. The decrease of LV mass can reach 30-50\% [28]. The reduction of LV dimensions and LV mass are classically associated with low energy intakes, BMI, and low T3 hormone level [12, 28, 29].

In parallel with cardiac morphological impairment, hemodynamically, patients with AN disclosed reduced cardiac output and hypotension [5, 12, 30-32]. De Simone et al. [4] reported reduction of the left ventricular mid-wall shortening, associated with reduced cardiac output in starving patients.

Myocardial systolic function may also be affected, and this feature is classically reversible with weight recovery [7]. Majority of patients discloses normal LV ejection fraction (LVEF). However, using tissue Doppler Imaging (TDI) and 2-dimensional strain imaging, submyocardial systolic impairments have been reported in AN. Also, sub-myocardial LV diastolic impairment may be present. Galetta et al. [33], in a study that included 20 female patients $(22.4 \pm 4.3$ years old $)$, reported not only a decrease of left ventricular TDI basal peak systolic velocities, but also a decrease of LV diastolic velocities. In addition, the authors found an association between reduced cardiac tissular velocities and indexed LV mass $(r=0.55, p<0.02)$ [33]. Escudero et al. [34] reported reduced diastolic peak TDI velocities in patients with AN. Eidem et al. [35] reported an increase of the myocardial performance index $(0.49 \pm 0.08$ in patients vs $0.35 \pm 0.03$ in control group) in patients with AN whereas LVEF was in normal range. Overt cardiac failure symptoms are rare. Rarely, patients may present myocardial infarction [36]. Finally, Tako-Tsubo cardiomyopathy may rarely occur, due to possible increase of catecholamine levels, related to profound hypoglycemia [37, 38]. Table 1 summarizes echocardiographic finding in the literature $[4,6,9,12,28,33-35,39-42]$. The myocardial dysfunction may be associated with electrolytic disturbances. Indeed, with starvation, reduction of phosphate stores, calcium, and potassium especially in purgative subtype of $\mathrm{AN}$, is classical and may be associated with impaired muscle contractility after several years of evolution of AN symptoms (chronic starvation leading to chronic underweight and chronic purgatives behaviors). Electrolytic abnormalities that include hypophosphatemia [43], hypomagnesemia [44], and hypokalemia can be associated with cardiac dysfunction. Moreover, selenium and thiamin deficiency have been reported to be associated with cardiac dysfunction [45].

Recently, magnetic resonance imaging merged as a radiological exam for the assessment of cardiac function in patients with AN. Magnetic resonance imaging is used to characterize myocardial function and fibrosis. In the study by Oflaz et al. [46], 23\% of patients with AN disclosed myocardial fibrosis (late gadolinium enhancement). The clinical long-term impact of this feature will need future studies.

\section{Pericardium}

Pericardial effusion is frequent (Fig. 1), ranging from 20 to $70 \%[41,47]$. In a study that included 173 patients aged between 12 and 17 years, Kastner et al. [41] reported a prevalence of pericardial effusion at $34 \%$. Cardiac tamponade have been reported in some published clinical cases, but this complication remains very rare $[48,49]$. The presence of pericardial effusion in $\mathrm{AN}$ 
Heart Fail Rev

t1.1 Table 1 Doppler-echocardiographic findings in patients with anorexia nervosa

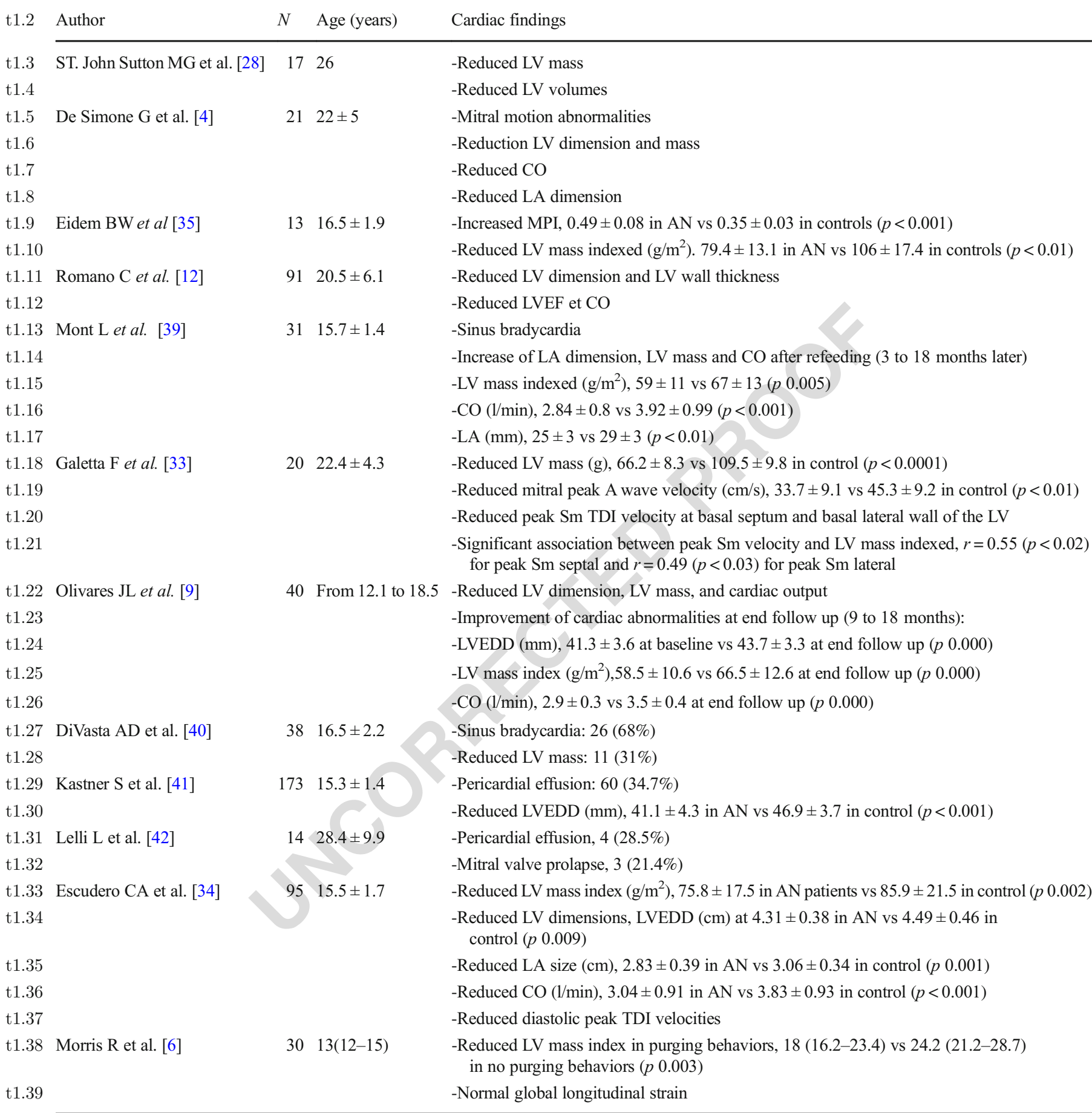

Data are expressed as mean $\pm \mathrm{SD}$ or median (interquartile range) or number (percentage)

$C O$, cardiac output; $H R$, heart rate; $M P I$, myocardial performance index; $L V$, left ventricle; $L V E D D$, left ventricular end diastolic diameter; $L V E F$, left ventricular ejection fraction; $L A$, left atrium; TDI, tissue Doppler imaging; $M P I$, myocardial performance index; $N$, number of patients; Ref, reference

159 has been reported to be associated with low BMI and 160 low T3 hormone levels [47]. Duration of illness and 161 low BMI are reported to be predictive factors for peri162 cardial effusion $[41,50]$.

\section{Mitral valve}

Mitral valve prolapse is frequent in patients with AN [25], 164 with a higher prevalence, ranging from 33 to $60 \%$ [51], 165 


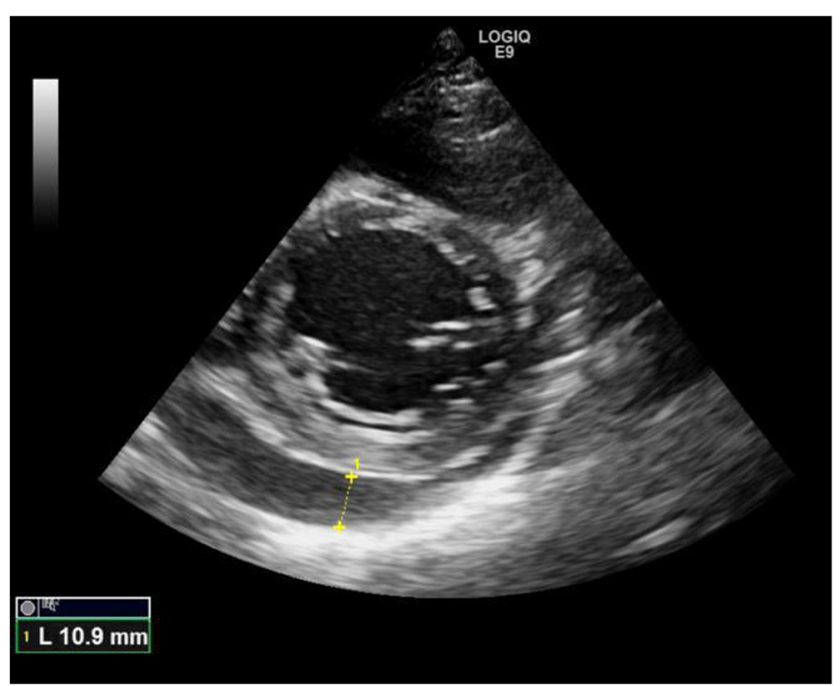

Fig. 1 Left ventricular two-dimensional echocardiogram from a parasternal short axis view showing a pericardial effusion in a patient with anorexia nervosa

without any association with BMI [46]. However, significant mitral regurgitation is rare.

\section{Evolution of cardiac impairment with weight recovery}

Cardiac abnormalities are generally reversible with weight recovery [39]. Left ventricular systolic dysfunction recovers with refeeding as well as LV dimensions. Gottdiener et al. [32] reported normalization of cardiac dimensions and LV mass with refeeding. Olivares et al. [9] reported an improvement of LV mass index, LV dimensions, and cardiac output, with weight restoration. Finally, with refeeding, pericardial effusion disappears. Kastner et al. [47] reported a remission of pericardial effusion in $88 \%$ of patients.

Also, the electrical abnormalities recover with refeeding. Indeed, with weight restoration, the sympathetic tone increases and the vagal tone decreases, providing normalization of heart rate [39, 52]. Kanbur et al. [20] reported a Mobitz I disappear with weight restoration in patients with AN with refeeding, it has been reported a reduction of the QT dispersion in patients with AN [53]. Cooke et al. [54] reported a QT interval prolongation recovery with refeeding in AN. Mont et al. [39] reported a decrease of QT dispersion and QT interval, as well as an increase of heart rate and normalization of heart rate variability with refeeding.

However, clinicians have to be careful with refeeding in patients with $\mathrm{AN}$, because of the risk of refeeding syndrome [55]. Congestive heart failure may occur during refeeding syndrome [30], in addition with the classical increase of the liver enzymes.
With refeeding, the patient shifts from an undernourished state to an artificial refeeding that is an anabolism statement; this phenomenon creates a significant metabolic modification with biochemical impairment due to insulin secretion, potassium cells intake. Hypophosphatemia is frequent in refeeding syndrome, as well as hypokalemia and hypomagnesemia in refeeding syndrome, and arrhythmia can occur in this situation [56].

\section{Mortality, sudden death, and anorexia}

Anorexia nervosa has the highest mortality rate among psychiatric disorders. In the study by Lowe et al. [57], which included 84 patients with a very long-term follow-up (21 years), the authors reported a standardized mortality rate at 9.8 , and $51 \%$ of patients recover from illness. In a British study, long-term mortality (20 years) has been reported, reaching $4 \%$ and $13 \%$ in two centers [58]. In an Italian study [59], with an 8 -year follow-up, mortality rate was $2.7 \%$. In Denmark, in a study that included patients with AN between 1970 and 1993 [60], crude mortality was 8.4\% with a standardized mortality ratio at 6.69. Sullivan et al. [61], in a metaanalysis that included 42 studies, reported a mortality rate at $5.6 \%$ per decade. In another meta-analysis that included patients with eating disorders from 36 studies, Arcelus et al. [62] reported a standardized mortality rate at 5.8. In a French study that included 601 patients with AN, Huas et al. [63] found a standardized mortality ratio at 10.6 and reported six factors associated with mortality: older age, history of suicide attempt, longer eating disorder duration, diuretic use, intensity of eating disorder symptoms, and BMI. Suicide and illness are the main causes of death [58].The other causes of death are cardiac failure, metabolic and electrolyte (notably by hypokalemia and/or hyphosphatemia) disorders, liver failure, hypoglycemic coma, sometimes gastric rupture in bulimia, and rarely cerebral hemorrhage [64-66].

However, half of deaths are due to suicide [66]. Patton et al. [67], in a study that included 460 patients with eating disorders, reported a six-fold increase in mortality, and suicide was found to be the main cause of death. The other factors associated with mortality are the presence of recurrent hospital admissions for eating disorders and the lowest weight at initial presentation.

Cardiac diseases account for at least $1 / 3$ of all causes of deaths in patients with AN [68]. The QT dispersion has been reported to a risk factor for sudden cardiac death in patients with AN. In the study by Isner et al. [69] that included tree anorexia patients who died suddenly, the authors reported ECG and necropsy findings and documented ventricular tachyarrhythmia in 2 patients (among them, one with torsade de pointe). Indeed, sudden death may be due to torsade de pointes [69]. However, in patients with QT interval 
prolongation, sudden death occurs particularly in case of absolute QT intervals more than $600 \mathrm{~ms}$. Ventricular arrhythmia may occur particularly in a patient with severe hypokalemia. In the study by Facchini et al. [70], that included 29 patients with under nourished AN (BMI at 13.8 \pm 1.5$)$, three patients disclosed severe hypokalemia $(<2 \mathrm{mEq} / \mathrm{l})$, and QTc was severely prolonged in 2 patients (QTc $600 \mathrm{~ms}$ and $650 \mathrm{~ms}$ ). A ventricular arrhythmia occurred in one patient among the two patients with severe QTc prolongation. Finally, Rivaldi et al. [31] reported the following parameters as predictive factors for sudden death in patients with AN: chronic hypokalemia, chronic hypo-albuminemia $<3.6 \mathrm{~g} / 100 \mathrm{ml}$, and chronic illness with duration $>10$ years.

\section{Conclusion}

Anorexia nervosa is a psychiatric eating disorder with higher morbidity and mortality. Cardiac impairments are frequent complications that require systematic cardiac noninvasive explorations especially for severe AN patients. Their clinical nutritional care must be conducted carefully to avoid cardiac impairment. Doppler echocardiography should be performed particularly in patients with severe undernutrition and during refeeding to assess left ventricular function, hemodynamic status, and cardiac preload.

\section{Compliance with ethical standards}

Conflict of interest The authors declare that they have no conflicts of interest.

\section{References}

1. Herzog W, Deter HC, Fiehn W, Petzold E (1997) Medical findings and predictors of long-term physical outcome in anorexia nervosa: a prospective, 12-year follow-up study. Psychol Med 27(2):269-279

2. Miller KK, Grinspoon SK, Ciampa J, Hier J, Herzog D, Klibanski A (2005) Medical findings in outpatients with anorexia nervosa. Arch Intern Med 165(5):561-566

3. (2013) American Psychiatric Association, Diagnostic and statistical manual of mental disorders, 338-45 (5th ed.).

4. de Simone G, Scalfi L, Galderisi M, Celentano A, Di Biase G, Tammaro P et al (1994) Cardiac abnormalities in young women with anorexia nervosa. Br Heart J 71(3):287-292

5. Goldberg SJ, Comerci GD, Feldman L (1988) Cardiac output and regional myocardial contraction in anorexia nervosa. J Adolesc Health Care 9(1):15-21

6. Morris R, Prasad A, Asaro J, Guzman M, Sanders L, Hauck A et al (2017) Markers of cardiovascular dysfunction in adolescents with anorexia nervosa. Glob Pediatr Health 4:2333794X17727423

7. Casiero D, Frishman WH (2006) Cardiovascular complications of eating disorders. Cardiol Rev 14(5):227-231

8. Di Cola G, Jacoangeli F, Jacoangeli F, Lombardo M, Iellamo F (2014) Cardiovascular disorders in anorexia nervosa and potential therapeutic targets. Intern Emerg Med 9(7):717-721
9. Olivares JL, Vázquez M, Fleta J, Moreno LA, Pérez-González JM, Bueno M (2005) Cardiac findings in adolescents with anorexia nervosa at diagnosis and after weight restoration. Eur J Pediatr 164(6):383-386

10. Sachs KV, Harnke B, Mehler PS, Krantz MJ (2016) Cardiovascular complications of anorexia nervosa: a systematic review. Int J Eat Disord 49(3):238-248

11. Takahashi S, Mine T (2016) An endomyocardial biopsy of the left ventricle in an anorexia nervosa patient with sinus bradycardia and left ventricular systolic dysfunction. Case Rep Cardiol 2016: 9805291

12. Romano C, Chinali M, Pasanisi F, Greco R, Celentano A, Rocco A, Palmieri V, Signorini A, Contaldo F, de Simone G (2003) Reduced hemodynamic load and cardiac hypotrophy in patients with anorexia nervosa. Am J Clin Nutr 77(2):308-312

13. Palla B, Litt IF (1988) Medical complications of eating disorders in adolescents. Pediatrics 81(5):613-623

14. Galetta F, Franzoni F, Prattichizzo F, Rolla M, Santoro G, Pentimone F (2003) Heart rate variability and left ventricular diastolic function in anorexia nervosa. J Adolesc Health 32(6):416421

15. Thurston J, Marks P (1974) Electrocardiographic abnormalities in patients with anorexia nervosa. Br Heart J 36(7):719-723

16. Krantz MJ, Sabel AL, Sagar U, Long CS, Barbey JT, White KVet al (2012) Factors influencing QT prolongation in patients hospitalized with severe anorexia nervosa. Gen Hosp Psychiatry 34(2):173-177

17. Dec GW, Biederman J, Hougen TJ (1987) Cardiovascular findings in adolescent inpatients with anorexia nervosa. Psychosom Med 49(3):285-290

18. Nudel DB, Gootman N, Nussbaum MP, Shenker IR (1984) Altered exercise performance and abnormal sympathetic responses to exercise in patients with anorexia nervosa. J Pediatr 105(1):34-37

19. Kollai M, Bonyhay I, Jokkel G, Szonyi L (1994) Cardiac vagal hyperactivity in adolescent anorexia nervosa. Eur Heart J 15(8): $1113-1118$

20. Kanbur NO, Goldberg E, Pinhas L, Hamilton RM, Clegg R, Katzman DK (2009) Second-degree atrioventricular block (Mobitz Type I) in an adolescent with anorexia nervosa: intrinsic or acquired conduction abnormality. Int J Eat Disord 42(6):575578

21. Bravender T, Kanter R, Zucker N (2006) Anorexia nervosa and second-degree atrioventricular block (Type I). Int J Eat Disord 39(7):612-615

22. Kossaify A (2010) Management of sinus node dysfunction with junctional escape rhythm in a case of anorexia nervosa. Turk Kardiyol Dern Ars 38(7):486-488

23. Lombardi F (1998) The QT interval and QT dispersion: 'the smaller, the better'. Eur Heart J 19(9):1279-1281

24. Hill JA, Friedman PL (1997) Measurement of QT interval and QT dispersion. Lancet 349(9056):894-895

25. Oka Y, Ito T, Sekine I, Sada T, Okabe F, Naito A, Matsumoto S, Suematsu H, Kuboki T, Nomura S (1984) Mitral valve prolapse in patients with anorexia nervosa. J Cardiogr 14(3):483-491

26. Krantz MJ, Donahoo WT, Melanson EL, Mehler PS (2005) QT interval dispersion and resting metabolic rate in chronic anorexia nervosa. Int J Eat Disord 37(2):166-170

27. Keys A (1950) The residues of malnutrition and starvation. Science 112(2909):371-373

28. St John Sutton MG, Plappert T, Crosby L, Douglas P, Mullen J, Reichek N (1985) Effects of reduced left ventricular mass on chamber architecture, load, and function: a study of anorexia nervosa. Circulation 72(5):991-1000

29. Silvetti MS, Magnani M, Santilli A, Di Liso G, Diamanti A, Pompei E et al (1998) The heart of anorexic adolescents. G Ital Cardiol 28(2):131-139 
30. Schocken DD, Holloway JD, Powers PS (1989) Weight loss and the heart. Effects of anorexia nervosa and starvation. Arch Intern Med 149(4):877-878

31. Ravaldi C, Vannacci A, Ricca V (2003) Cardiac complications of anorexia nervosa. Recenti Prog Med 94(6):267-270

32. Gottdiener JS, Gross HA, Henry WL, Borer JS, Ebert MH (1978) Effects of self-induced starvation on cardiac size and function in anorexia nervosa. Circulation 58(3 Pt 1):425-433

33. Galetta F, Franzoni F, Cupisti A, Morelli E, Santoro G, Pentimone F (2005) Early detection of cardiac dysfunction in patients with anorexia nervosa by tissue Doppler imaging. Int J Cardiol 101(1):33

34. Escudero CA, Potts JE, Lam PY, De Souza AM, Mugford GJ, Sandor GG (2016) An echocardiographic study of left ventricular size and cardiac function in adolescent females with anorexia nervosa. Eur Eat Disord Rev 24(1):26-33

35. Eidem BW, Cetta F, Webb JL, Graham LC, Jay MS (2001) Early detection of cardiac dysfunction: use of the myocardial performance index in patients with anorexia nervosa. J Adolesc Health 29(4):267-270

36. García-Rubira JC, Hidalgo R, Gómez-Barrado JJ, Romero D, Cruz Fernández JM (1994) Anorexia nervosa and myocardial infarction. Int J Cardiol 45(2):138-140

37. Ohwada R, Hotta M, Kimura H, Takagi S, Matsuda N, Nomura K, Takano K (2005) Ampulla cardiomyopathy after hypoglycemia in three young female patients with anorexia nervosa. Intern Med 44(3):228-233

38. Volman MN, Ten Kate RW, Tukkie R (2011) Tako Tsubo cardiomyopathy, presenting with cardiogenic shock in a 24-year-old patient with anorexia nervosa. Neth J Med 69(3):129-131

39. Mont L, Castro J, Herreros B, Paré C, Azqueta M, Magriña J, Puig J, Toro J, Brugada J (2003) Reversibility of cardiac abnormalities in adolescents with anorexia nervosa after weight recovery. J Am Acad Child Adolesc Psychiatry 42(7):808-813

40. DiVasta AD, Walls CE, Feldman HA, Quach AE, Woods ER, Gordon CM, Alexander ME (2010) Malnutrition and hemodynamic status in adolescents hospitalized for anorexia nervosa. Arch Pediatr Adolesc Med 164(8):706-713

41. Kastner S, Salbach-Andrae H, Renneberg B, Pfeiffer E, Lehmkuhl U, Schmitz L (2012) Echocardiographic findings in adolescents with anorexia nervosa at beginning of treatment and after weight recovery. Eur Child Adolesc Psychiatry 21(1):15-21

42. Lelli L, Rotella F, Castellini G, Benni L, Lo Sauro C, Barletta G, Mannucci E, Castellani S, di Tante V, Galanti G, Ricca V (2015) Echocardiographic findings in patients with eating disorders: a case-control study. Nutr Metab Cardiovasc Dis 25(7):694-696

43. Cariem AK, Lemmer ER, Adams MG, Winter TA, O'Keefe SJ (1994) Severe hypophosphataemia in anorexia nervosa. Postgrad Med J 70(829):825-827

44. Davidson A, Anisman PC, Eshaghpour E (1992) Heart failure secondary to hypomagnesemia in anorexia nervosa. Pediatr Cardiol 13(4):241-242

45. Winston AP, Jamieson CP, Madira W, Gatward NM, Palmer RL (2000) Prevalence of thiamin deficiency in anorexia nervosa. Int J Eat Disord 28(4):451-454

46. Oflaz S, Yucel B, Oz F, Sahin D, Ozturk N, Yaci O, Polat N, Gurdal A, Cizgici AY, Dursun M, Oflaz H (2013) Assessment of myocardial damage by cardiac MRI in patients with anorexia nervosa. Int $\mathrm{J}$ Eat Disord 46(8):862-866

47. Inagaki $\mathrm{T}$, Yamamoto $\mathrm{M}$, Tsubouchi $\mathrm{K}$, Miyaoka $\mathrm{T}$, Uegaki J, Maeda T et al (2003) Echocardiographic investigation of pericardial effusion in a case of anorexia nervosa. Int J Eat Disord 33:364-366

48. Kircher JN, Park MH, Cheezum MK, Hulten EA, Kunz JS, Haigney M, Atwood JE (2012) Cardiac tamponade in association with anorexia nervosa: a case report and review of the literature. Cardiol J 19(6):635-638
49. Polli N, Blengino S, Moro M, Zappulli D, Scacchi M, Cavagnini F (2006) Pericardial effusion requiring pericardiocentesis in a girl with anorexia nervosa. Int J Eat Disord 39:609-611

50. Docx MK, Gewillig M, Simons A, Vandenberghe P, Weyler J, Ramet J, Mertens L (2010) Pericardial effusions in adolescent girls with anorexia nervosa: clinical course and risk factors. Eat Disord 18(3):218-225

51. Johnson GL, Humphries LL, Shirley PB, Mazzoleni A, Noonan JA (1986) Mitral valve prolapse in patients with anorexia nervosa and bulimia. Arch Intern Med 146(8):1525-1529

52. Ulger Z, Gürses D, Ozyurek AR, Arikan C, Levent E, Aydoğdu S (2006) Follow-up of cardiac abnormalities in female adolescents with anorexia nervosa after refeeding. Acta Cardiol 61(1):43-49

53. Bär KJ, Boettger S, Wagner G, Wilsdorf C, Gerhard UJ, Boettger MK, Blanz B, Sauer H (2006) Changes of pain perception, autonomic function, and endocrine parameters during treatment of anorectic adolescents. J Am Acad Child Adolesc Psychiatry 45(9): 1068-1076

54. Cooke RA, Chambers JB, Singh R, Todd GJ, Smeeton NC, Treasure J, Treasure T (1994) QT interval in anorexia nervosa. Br Heart J 72(1):69-73

55. Golden NH, Meyer W (2004) Nutritional rehabilitation of anorexia nervosa. Goals and dangers. Int J Adolesc Med Health 16(2):131144

56. Mehanna HM, Moledina J, Travis J (2008) Refeeding syndrome: what it is, and how to prevent and treat it. BMJ 336(7659):14951498

57. Löwe B, Zipfel S, Buchholz C, Dupont Y, Reas DL, Herzog W (2001) Long-term outcome of anorexia nervosa in a prospective 21-year follow-up study. Psychol Med 31(5):881-890

58. Crisp AH, Callender JS, Halek C, Hsu LK (1992) Long-term mortality in anorexia nervosa. A 20-year follow-up of the St George's and Aberdeen cohorts. Br J Psychiatry 161:104-107

59. Signorini A, De Filippo E, Panico S, De Caprio C, Pasanisi F, Contaldo F (2007) Long-term mortality in anorexia nervosa: a report after an 8-year follow-up and a review of the most recent literature. Eur J Clin Nutr 61(1):119-122

60. Emborg C (2001) Mortality and causes of death in patients with eating disorders in Denmark, 1970-1993. Ugeskr Laeger 163(25): 3476-3480

61. Sullivan PF (1995) Mortality in anorexia nervosa. Am J Psychiatry 152(7):1073-1074

62. Arcelus J, Mitchell AJ, Wales J, Nielsen S (2011) Mortality rates in patients with anorexia nervosa and other eating disorders. A metaanalysis of 36 studies. Arch Gen Psychiatry 68(7):724-731

63. Huas C, Caille A, Godart N, Foulon C, Pham-Scottez A, Divac S, Dechartres A, Lavoisy G, Guelfi JD, Rouillon F, Falissard B (2011) Factors predictive of ten-year mortality in severe anorexia nervosa patients. Acta Psychiatr Scand 123(1):62-70

64. Herzog DB, Copeland PM (1985) Eating disorders. N Engl J Med 313(5):295-303

65. Turillazzi E, Bello S, Neri M, Pomara C, Riezzo I, Fineschi V (2013) Congestive heart failure as cause of death in an anorexia nervosa fatal case. Int J Cardiol 165(2):e28-e29

66. Steinhausen HC, Seidel R (1993) Outcome in adolescent eating disorders. Int J Eat Disord 14(4):487-496

67. Patton GC (1988) Mortality in eating disorders. Psychol Med 18(4): 947-951

68. Neumärker KJ (1997) Mortality and sudden death in anorexia nervosa. Int J Eat Disord 21(3):205-212

69. Isner JM, Roberts WC, Heymsfield SB, Yager J (1985) Anorexia nervosa and sudden death. Ann Intern Med 102(1):49-52

70. Facchini M, Sala L, Malfatto G, Bragato R, Redaelli G, Invitti C (2006) Low-K+ dependent QT prolongation and risk for ventricular arrhythmia in anorexia nervosa. Int J Cardiol 106(2):170-176 